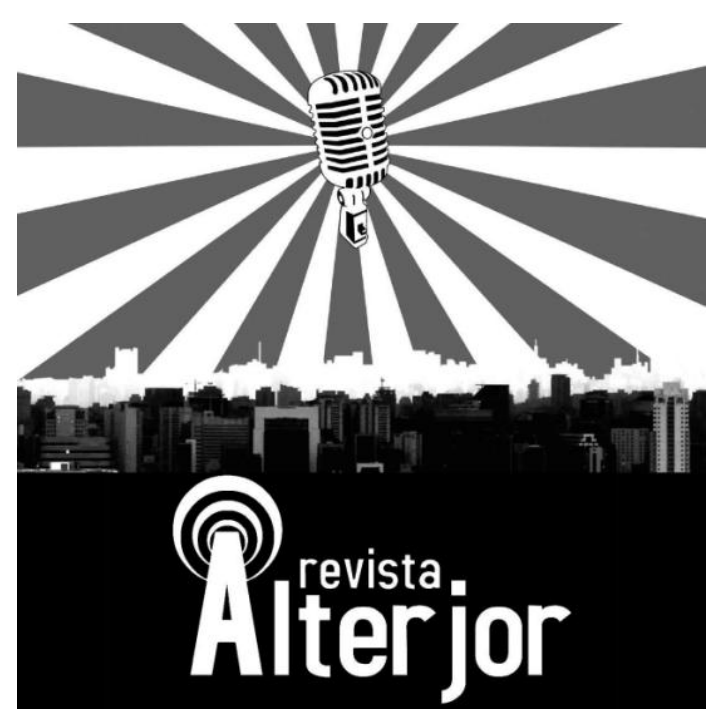

\title{
JORNALISMO ÉTICO, LIBERDADE DE EXPRESSÃO E CREDIBILIDADE: DILEMAS DO PROFISSIONAL DE JORNALISMO NAS MÍDIAS SOCIAIS
}

\author{
Edwaldo Costa $^{1}$ \\ Marcos Simas $^{2}$
}

\begin{abstract}
RESUMO: O presente artigo analisa o impacto da postura adotada pelo profissional de jornalismo nas mídias sociais sobre a credibilidade desse profissional, dos veículos de comunicação e, numa visão mais ampla, da própria atividade de jornalismo, abordando aspectos como a ética da profissão e a liberdade de expressão. Nesse sentido, o objetivo geral é analisar, sob o ponto de vista do profissional de jornalismo, como declarações públicas de cunho político ou ideológico, principalmente nas mídias sociais, podem comprometer a própria imagem e a credibilidade do veículo em que trabalha. Conclui-se que, nos tempos atuais, a conduta do jornalista nas mídias sociais, principalmente no que tange a posicionamentos pessoais políticos ou ideológicos, tem potencial para comprometer sua credibilidade profissional.
\end{abstract}

PALAVRAS-CHAVE: Jornalismo. Ética. Política. Mídias sociais.

ABSTRACT: This article analyzes the impact of the posture adopted by the journalism professional on social media on the credibility of this professional, on the media and, in a broader view, on the journalism activity itself, addressing aspects such as the ethics of the profession and the freedom of expression. In this sense, the general objective is to analyze, from the point of view of the journalism professional, how public statements of a political or ideological nature, especially in social media, can compromise the very image and credibility of the vehicle in which he works. It is concluded that, in the current times, the journalist's conduct on social media, especially with regard to personal political or ideological positions, has the potential to compromise his professional credibility.

KEYWORDS: Journalism. Ethic. Politics. Social media.

\footnotetext{
${ }^{1}$ Pós-doutor em Jornalismo pela Universidade de São Paulo (ECA/USP). E-mail: edwaldocosta1 @ gmail.com.

${ }^{2}$ Pós-graduado em Gestão da Comunicação nas Organizações pelo Centro Universitário de Brasília (UniCEUB). Email:marcos_simas@msn.com.
}

Revista ALTERJOR

Grupo de Estudos Alterjor: Jornalismo Popular e Alternativo (ECA-USP)

Ano 10 Volume ol Edição 23 Janeiro-Julho de 202l

Avenida Professor Lúcio Martins Rodrig̉ues, 443, Cidade Universitária, São Paulo, CEP: 05508-020 


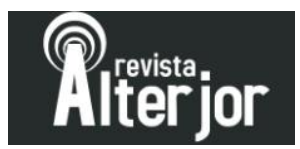

\section{INTRODUÇÃO}

O modelo apartidário de jornalismo é construído em torno da norma de cobrir a política como se todos os lados fossem igualmente culpados de todas as ofensas. Os meios de comunicação tomam decisões sobre como se posicionar dentro do mercado e como sinalizar para os novos consumidores que tipos de meios eles são em termos ideológicos. Segundo Nalini (2015), eles também interagem estrategicamente com os políticos, que usam as inclinações ideológicas dos jornalistas e acusações de inclinações para minar a credibilidade até das críticas mais válidas.

Assim como os incentivos de mercado apoiaram o desenvolvimento de uma imprensa neutra, estes mesmos incentivos, combinados à tecnologia, permitiram às instituições fornecerem cobertura de notícias a partir de perspectivas decididamente conservadoras (ou "de direita") ou progressistas (ou "de esquerda"). No mesmo caminho, os diversos canais da Internet fragmentaram ainda mais o ambiente de mídia em nichos ideológicos estreitos.

As mídias sociais são as plataformas mais populares para divulgar e discutir tudo o que acontece na atualidade. De fato, são tão populares que hoje parece impossível que os jornalistas existam fora delas. Nesse contexto, há que se destacar o microblog Twitter, atualmente percebido como a principal ferramenta para a divulgação do próprio pensamento.

De acordo com Assis (2017), as notícias viajam mais rápido quando são publicadas segundos após o evento acontecer e, com 6.000 tweets sendo enviados a cada segundo, essa mídia social mudou a face do jornalismo para sempre. Hoje, o Twitter é ferramenta fundamental para a atuação do jornalista.

A credibilidade é valor necessário e indispensável ao profissional de jornalismo. Ela está tão intrinsecamente associada à profissão que há normalmente uma predisposição à confiança. Por isso, nos dias atuais, tantos jornalistas são elevados à nova categoria de formadores de opinião. Dessa forma, a conduta desses profissionais estará sempre em constante e relevante evidência, e a manifestação de seus 


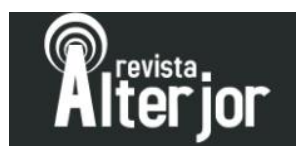

posicionamentos pessoais terá grande influência na formação de opinião, uma vez que grande parte do público não consegue diferenciar o profissional do cidadão.

Este artigo buscará, como objetivo geral, analisar em que medida a manifestação pública do posicionamento político ou ideológico do profissional de jornalismo, por meio de seus perfis pessoais nas mídias sociais, pode comprometer sua credibilidade ou do veículo em que trabalha.

A presente pesquisa, por meio de seus objetivos específicos buscará apresentar a influência de novas tecnologias e das mídias sociais na vida das pessoas, especialmente na atividade de jornalismo, pontuar aspectos relacionados à ética do jornalismo, refletir sobre liberdade de expressão e, por fim, apresentar alguns exemplos do uso de mídias sociais por jornalistas para posicionamento político ou ideológico.

Justifica-se o presente trabalho como um meio de contribuir para o ambiente acadêmico, contextualizando, enriquecendo e provocando reflexões sobre temáticas relacionadas à ética do jornalismo, ao papel do jornalismo em uma sociedade democrática e à liberdade de expressão e opinião. A pesquisa também pretende ser um mecanismo simplificador de tais discussões, buscando apresentar um material conciso e de fácil assimilação, mesmo para leitores que estiverem iniciando sua busca por conhecimento sobre o tema.

Aponta-se que a pesquisa desse tema é fundamental para apoiar a evolução do conhecimento no campo de estudo abordado, ou seja, através dos resultados aqui apresentados, tem-se o objetivo de ampliar os horizontes sobre o tema da convivência da imagem profissional do jornalista e de sua imagem pessoal nas mídias sociais.

Para o desenvolvimento do conteúdo, foi adotada a metodologia da análise feita diretamente sobre as publicações feitas por jornalistas no Twitter e suas consequências no cenário da divulgação de notícias. Nesse sentido, a construção do material visa alcançar resultados que confirmem as hipóteses levantadas, a partir de situações de conhecimento público, vivenciadas por profissionais de jornalismo.

Buscou-se, para o desenvolvimento deste artigo, a realização de pesquisa bibliográfica, utilizando artigos publicados em revistas e na Internet, livros, periódicos e 


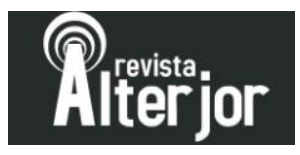

outras fontes disponíveis. A pesquisa bibliográfica possui como foco explicar e levantar uma discussão sobre o tema abordado, sendo sempre embasada por referências teóricas. Ela também objetiva, por meio do conhecimento e das análises dos autores referenciados, enriquecer as reflexões pertinentes ao tema.

Foi adotado, ainda, o modelo de leitura conhecido como "modelo de leitura seletiva". De acordo com esse modelo, a leitura é realizada com profundidade, a fim de levantar material consistente para o estudo.

Por fim, também se mostrou importante e válida a realização de uma leitura analítica de todo o material levantado e formulado, para que fosse possível a ordenação e a sumarização das informações. Neste ponto, considerou-se aquelas informações que se mostraram auxiliadoras ou norteadoras para o alcance da resposta do problema de pesquisa e dos objetivos da pesquisa.

\section{JORNALISMO NA VIDA DAS PESSOAS}

O jornalismo refere-se à coleta, preparação e distribuição de notícias e comentários relacionados e materiais de destaque por meio de mídia impressa e eletrônica, como jornais, revistas, livros, blogs, webcasts, podcasts, sites, redes e mídias sociais, e-mail, além de rádio, filmes e televisão.

Segundo Martins (2010), a palavra jornalismo foi originalmente aplicada à reportagem de eventos atuais em formato impresso, especificamente jornais. No século 20, no entanto, com o advento do rádio, da televisão e, por fim, da Internet, o uso do termo foi ampliado para incluir todas as comunicações impressas e eletrônicas relacionadas a assuntos atuais.

O jornalismo possui como foco criar, reunir e apresentar notícias e informações a seus públicos, sendo ele, portanto, um produto dessas atividades. A diferenciação entre as atividades do jornalismo e as demais reside em suas características e práticas identificáveis. 


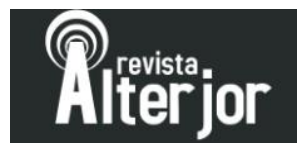

Na visão de Santaella e Lemos (2010), esses elementos não apenas separam o jornalismo de outras formas de comunicação, mas também o tornam indispensável para as sociedades democráticas. A História revela que, quanto mais democrática é uma sociedade, mais notícias e informações ela tende a ter.

Notícia é a parte da comunicação que mantém a população informada sobre os eventos, questões e personagens em mudança no mundo exterior. Segundo Velo (2012), embora possa ser interessante ou até divertida, o principal valor das notícias é seu caráter utilitário, que capacita os informados.

O objetivo do jornalismo não é definido pela tecnologia, pelos jornalistas ou pelas técnicas que eles empregam. Moraes, Ramonet e Serrano (2013) citam que em vez disso, "os princípios e o objetivo do jornalismo são definidos por algo mais básico: a função que as notícias desempenham na vida das pessoas”.

\subsection{Obrigação com a verdade}

Uma boa tomada de decisão depende de pessoas com fatos confiáveis e precisos colocados em um contexto significativo. Silva e Tasso (2012) citam que o Jornalismo não busca a verdade em um sentido absoluto ou filosófico, mas em uma capacidade que é mais realista.

O autor Barsotti (2014), explica que tudo o que é apontado como verdade, incluindo leis comprovadas cientificamente, devem ser submetidas à revisão, porém isso não ocorre porque tais verdades e leis são necessárias e funcionam perfeitamente. Assim, o jornalismo procura ser uma forma prática e funcional da verdade. Essa verdade não possui um sentido filosófico, absoluto ou científico. Trata-se, sim, de uma verdade possível de ser operada no cotidiano.

O conceito de "verdade jornalística" tem início quando o profissional compreende a importância de reunir e verificar as informações e inclui estas atividades em seu fluxo produtivo cotidiano. Karam (2014) defende que é a partir dessa compreensão que os jornalistas conseguem transmitir relatos e informações justas e confiáveis. 


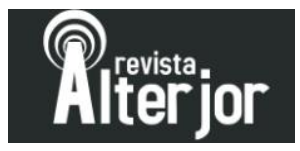

A cada dia, as pessoas se deparam com um volume crescente de informações e, nesse cenário, maior é a busca por provedores confiáveis, que forneçam informações verídicas, que tenham sido verificadas e abordadas no contexto correto.

É essencial que jornalistas trabalhem com transparência e isso inclui as fontes e métodos utilizados para coletar informações. Quem irá avaliar a informação é o público.

Nos dias atuais, após o advento das mídias sociais, qualquer cidadão ganhou um espaço para expressar suas opiniões, com grande possibilidade de que sua voz seja efetivamente ouvida. Nessas mídias, cada usuário tem potencial para influenciar um número expressivo de pessoas. Nesse contexto, é importante que o profissional de jornalismo tenha em mente que "a voz" a ser levantada sobre os fatos deve ser a do público. É ele que irá “julgar” o contexto e a interpretar as informações noticiadas.

\subsubsection{Lealdade aos cidadãos}

Primo (2013), explica que o editor de jornalismo - seja uma empresa de mídia que responda a anunciantes e acionistas ou um influenciador digital por meio de um blog, canal ou perfil nas mídias sociais, com suas próprias crenças e prioridades pessoais - deve demostrar uma fidelidade final aos cidadãos. Dessa forma, é importante que o interesse público e a propagação da verdade estejam acima de qualquer interesse ou suposições pessoais. "Eles devem se esforçar para colocar o interesse público e a verdade, acima de seus próprios interesses ou suposições” (PRIMO, 2013).

Velo (2012) aponta que o compromisso com os cidadãos é uma aliança implícita com o público e uma base do modelo de negócio jornalístico. O jornalismo fornecido "sem medo ou favor" é percebido como mais valioso do que o conteúdo de outras fontes de informação. Além disso, o compromisso com os cidadãos também faz com que o jornalismo seja um agente importante, capaz de apresentar uma imagem representativa dos grupos constituintes da sociedade.

A teoria subjacente à indústria moderna de notícias tem sido a crença de que a credibilidade cria um público amplo e leal. Nesse sentido, Cezar (2014) aborda que os 


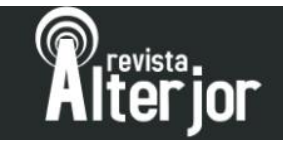

empresários de uma organização de notícias também devem nutrir - e não explorar sua lealdade ao público antes de outras considerações.

A tecnologia sempre esteve em constante mudança, entretanto quando a confiança do público é conquistada e nutrida, ela perdura, apesar de qualquer transformação tecnológica.

\subsubsection{Importância da verificação}

A verificação das informações é elemento intrínseco da ética do jornalista. Embora não exista um código padronizado, todo jornalista responsável e ético usa certos métodos para avaliar e testar as informações.

Segundo Barsotti (2018), ser imparcial ou neutro não é um princípio central do jornalismo. Como o jornalista precisa tomar decisões, ele não é e não pode ser objetivo. Todavia, os métodos jornalísticos devem ser objetivos.

Quando o conceito de objetividade surgiu originalmente, não implicava que os jornalistas estivessem livres de preconceitos. Apelou-se, antes, a um método consistente de testar informações, uma abordagem transparente às evidências, exatamente para que preconceitos pessoais e culturais não prejudicassem a precisão do trabalho. Ou seja, o método é objetivo, não o jornalista.

Procurar várias testemunhas, divulgar o máximo possível sobre fontes ou pedir comentários a vários lados, tudo indica tais padrões. Nalini (2015), cita que é justamente essa disciplina de verificação que separa o jornalismo de outras formas de comunicação, como propaganda, publicidade, ficção ou entretenimento.

\subsubsection{Independência}

A credibilidade aponta ter uma base fundamental: a independência. Segundo Sacramento (2018), esse termo indica que o jornalista não pode se deixar levar por fonte, ser intimidado por quem possui poder, tampouco por interesse próprio ou pessoal. 


\title{
Ritieior
}

É essencial que essa independência esteja atrelada à mente aberta e à curiosidade intelectual do jornalista, pois isso irá norteá-lo a enxergar além de sua própria realidade.

Contudo, independência jornalística, escrevem Kovach e Rosenstiel (2003), não é neutralidade.

\begin{abstract}
Embora os editorialistas e comentaristas não sejam neutros, as fontes de sua credibilidade ainda são a precisão, a justiça intelectual e a capacidade de informar - e não a devoção a determinado grupo ou resultado. Na independência, no entanto, os jornalistas devem evitar se entregarem à arrogância, ao elitismo, ao isolamento ou ao niilismo (Kovach e Rosenstiel, 2003).
\end{abstract}

Para se ter independência é preciso, principalmente, não ser seduzido por fontes, intimidado pelo poder ou visar interesse próprio.

\subsection{LIBERDADE DE EXPRESSÃO}

O Brasil experimentou o estabelecimento de uma estrutura constitucional "pósredemocratização" que, sem dúvida, concede liberdade de expressão e de imprensa. $O$ país preparou o terreno para o estabelecimento de um sistema de comunicação social alinhado com os mais avançados regimes internacionais no campo (MACCALÓZ, 2012).

A Constituição Federal do Brasil (1988) garante aos brasileiros um amplo acesso à informação de fontes diferentes e múltiplas, em um ambiente democrático em que a liberdade de expressão e de imprensa são garantidas. No entanto, o país ainda enfrenta algumas lacunas no quadro regulatório da mídia.

A Carta Magna de 1988 conta com uma legislação infraconstitucional de 1962, que, portanto, não responde aos novos desafios sociais e políticos brasileiros ou à revolução tecnológica do setor de comunicação e informação vivenciada nas últimas décadas. O país ainda precisa ir além na diversificação de suas fontes de informação, expandindo-as para os canais de comunicação do governo e da comunidade (SILVA e TASSO, 2012). 
É importante saber distinguir liberdade de expressão de liberdade de imprensa, pois têm naturezas distintas. Enquanto a liberdade de imprensa surge da reivindicação de profissionais do jornalismo, a liberdade de expressão é fundamentada na possibilidade de qualquer pessoa se manifestar.

Segundo Irina Bokova (2016), diretora-geral da UNESCO, a liberdade de expressão é um direito humano fundamental que alicerça todas as outras liberdades civis. Ela é vital para o Estado de Direito e para a boa governança, além de ser uma base para sociedades do conhecimento inclusivas e abertas. A liberdade de expressão está no cerne da liberdade midiática, assim como da prática do jornalismo, como uma forma de expressão que aspira ser de interesse público.

A liberdade de expressão, assim como seus desdobramentos de liberdade de informação e liberdade de imprensa, aplica-se aos tradicionais veículos de comunicação impressos e de rádio, bem como ao online. Essas liberdades são cruciais para o desenvolvimento sustentável, a democracia e o diálogo.

\section{3 ÉTICA JORNALÍSTICA}

O código de ética do jornalista brasileiro não especifica que um jornalista não possa se posicionar publicamente sobre o que pensa. Ele estabelece que o jornalista deve zelar em divulgar apenas a verdade e que a população seja informada dela, sem manipulação de informações ou ideologias, ou seja, um jornalista, diferente de um comentarista, não possui a função de opinar sobre determinado fato e sim informar o ocorrido. Moraes, Ramonet e Serrano (2013) acrescentam que o jornalista não deve manipular a informação, nem utilizá-la em benefício próprio.

Outro aspecto importante nesse contexto é atentar para o fato de que os profissionais de jornalismo, principalmente aqueles mais renomados e que atuam em veículos de grande alcance, dificilmente serão percebidos pelos públicos sob uma ótica que isole o profissional do cidadão. Ao contrário, percebe-se a formação de uma forte a associação que, muitas vezes se expande e se vincula também ao veículo em que trabalha. 


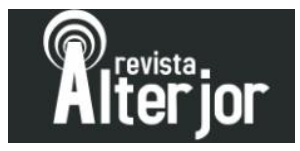

Nesse contexto, quando jornalistas se manifestam em suas redes sociais pessoais, podem colocar sua imparcialidade profissional sob o julgamento do público. Isso ocorre principalmente quando o conteúdo postado envolve questões polêmicas, como é o caso de posicionamentos políticos, principalmente no atual cenário de polarização vivenciado no Brasil.

Não há dúvidas de que, como qualquer cidadão, o jornalista tem o direito de se expressar. Há, entretanto, uma questão inexorável de gestão de risco de imagem profissional que se coloca diante desses profissionais. Perguntas como as seguintes materializam esta reflexão: É possível dissociar minhas opiniões pessoais de minha produção jornalística? Devo autorrestringir minha liberdade de expressão? Minha credibilidade profissional pode ser arranhada? Qual seria a extensão dos danos?

Há diversas situações, normais para qualquer cidadão, que podem colocar os profissionais de jornalismo diante desse tipo de impasse, como: a participação em protestos, a declaração pública de apoio a determinada candidatura política, a doação de recursos financeiros para campanhas políticas etc. No caso do jornalista, tais atos podem ser vistos como incompatíveis com a profissão, uma vez que poderiam suscitar dúvidas sobre eventual enviesamento e manipulação das informações noticiadas, de forma a alinhá-las a suas convicções e ideologias pessoais.

\subsection{O USO DE MÍDIAS SOCIAIS POR JORNALISTAS E POSICIONAMENTO POLÍ́TICO}

Junto ao avanço tecnológico, o jornalismo foi beneficiado pelo surgimento dos computadores, da Internet, das mídias sociais e dos dispositivos móveis. Assim, ele evoluiu e passou a fazer uso dessas ferramentas para a propagação de notícias.

O surgimento das mídias sociais é um aspecto significativo do sistema de mídia híbrido atual, que enfoca as interações entre atores políticos, a mídia e o público.

Depois da explosão das redes planetárias de comunicação e da WWW (World Wide Web), o uso das palavras "hibridismo", "híbrido" e "hibridização" ou "hibridação" expandiu-se consideravelmente para se 


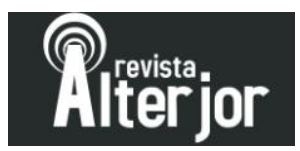

referir tanto à convergência das mídias no mundo digital quanto à mistura de linguagens na hipermídia, ou seja, a junção do hipertexto com a multimídia que define a linguagem que é própria das redes. Além de significar a mistura daquilo que é diverso, o hibridismo foi tomando conta de vários níveis da realidade: das culturas contemporâneas às mídias, tal como se apresentam nas redes de comunicação, e, na raíz das mídias, encontra-se o hibridismo entre os signos textuais, sonoros e visuais que por elas circulam. (SANTAELLA, 2009).

Assis (2017) afirma que o advento das redes sociais também é compreendido como grande avanço tecnológico em todas as áreas da sociedade. Essas plataformas passaram a ser usadas pelos veículos de informação e também, em âmbito particular, por seus profissionais.

Mídia social é um ambiente democrático, que permite ao usuário se comunicar, interagir e compartilhar informações, exercendo na plenitude sua liberdade de expressão. Segundo Alves (2012), dessa forma, qualquer pessoa pode se posicionar diante de um fato, ideologia ou pensamento, respeitando a Constituição e o direito de outros usuários.

Se a opinião pública é "um conceito contestado e maleável", é importante compreender as maneiras pelas quais ela é construída, principalmente por elites, como jornalistas, que nos fornecem diversas opiniões, por meio da cobertura de notícias de extrema importância para a prática da Democracia.

Porém, para Sacramento (2018), o significado da opinião pública é contingente: o clima social, o ambiente tecnológico e o ambiente de comunicação em qualquer estado democrático, juntos, determinam a maneira como pensamos sobre a opinião pública e as maneiras pelas quais tentamos medi-la.

Barsotti (2018) aponta que a partir do contexto político vivido no Brasil há alguns anos é muito comum que as pessoas se posicionem sobre o que acreditam, o que defendem, seus motivos, pensamentos etc. Na Internet não é diferente e qualquer publicação efetuada por um usuário, que, mediante seu direito de liberdade de expressão, pode decidir sobre o quê falar, rapidamente pode ser replicada e propagada no ambiente virtual, podendo alcançar um grande número de usuários. 


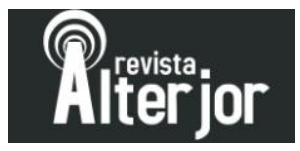

Pessoas consideradas influenciadores digitais, por possuírem número expressivo de seguidores nas mídias sociais, têm a oportunidade e a possibilidade de, ao divulgarem seus pensamentos, influenciarem a opinião de seu público cativo.

Tem sido comum encontrar nessas mídias jornalistas que se posicionam quanto a sua ideologia política. A questão aqui é justamente uma palavra citada anteriormente: influência. Jornalistas renomados, que atuam em grandes veículos de comunicação, comumente possuem um grande público em suas plataformas de redes sociais, e, em seu direito, como cidadãos, manifestam seus pensamentos resguardados pela própria Constituição Federal.

A jornalista Rachel Sheherazade, conhecida âncora de importante telejornal da TV aberta brasileira, após ter passado a externar determinadas opiniões políticas, sofreu inúmeras críticas e se envolveu em polêmicas nas mídias sociais, que culminaram com sua demissão antes do encerramento de seu contrato com a emissora. Na ocasião, a própria emissora foi muito questionada e pressionada.

Outro renomado profissional afastado das funções após manifestar posicionamentos relacionados a questões políticas foi Luís Ernesto Lacombe, apresentador de programa em outra grande emissora de TV aberta nacional.

Cabe notar que em ambos os casos as dificuldades surgiram em proporções análogas, ou seja, independentemente da orientação política manifestada - de "esquerda" ou de "direita”, favorável ou não ao governo.

Âncora e editor-chefe do telejornal de maior alcance da TV aberta brasileira, William Bonner (2020) diz evitar abordar temas políticos em suas redes sociais para não se envolver em confrontos ideológicos e que as redes sociais virou campo de batalha. Já seu colega de emissora, César Tralli, não se furta a manifestar suas opiniões.

O confronto nas redes, aliás, é fenômeno que traz insegurança aos profissionais de imprensa. A "Cartilha sobre medidas legais para proteção de jornalistas contra ameaças e assédio online", editada pela Associação Brasileira de Jornalismo Investigativo (ABRAJI), OAB e Observatório de Liberdade de Imprensa, diz que "O assédio contra jornalistas brasileiros nas redes sociais é um fenômeno em crescimento 


\section{Ritieior}

nos últimos anos. Jornalistas que veiculam reportagens sobre questões políticas ou sociais de natureza controversa se veem crescentemente como alvos de abusos praticados nas redes sociais, como comentários ofensivos e ameaças de violência física ou sexual. Embora esse tipo de retaliação seja comum a todos os jornalistas, percebe-se que, em particular, as jornalistas mulheres vivenciam ataques puramente relacionados à condição de gênero. Em alguns casos, ainda se pode constatar a ocorrência de uma campanha organizada por grupos de interesse para constranger e silenciar os jornalistas".

Bom exemplo de tais ataques foi a jornalista Patrícia Campos Mello, vinculada a tradicional jornal do país, que após ter sido acusada de assédio sexual por funcionário de uma empresa de disparos em massa nas redes sociais durante depoimento à CPMI das fake news no Congresso Nacional, virou alvo de inúmeros ataques ofensivos nas mídias sociais.

\section{CONSIDERAÇÕES FINAIS}

A partir do tema abordado e por meio da metodologia utilizada, foi possível realizar uma pesquisa que validasse as hipóteses levantadas.

Por meio desta pesquisa é possível compreender que, no exercício da liberdade de expressão, principalmente após o advento da Internet, das mídias sociais e dos dispositivos móveis, o cidadão comum ganhou voz e agora suas opiniões têm potencial para, em uma questão de segundos, alcançar milhares de pessoas por todo o planeta.

Como qualquer outro cidadão, os profissionais de jornalismo estão inseridos nessa nova realidade, repleta de potencialidades, mas também de desafios. Desses profissionais, a conjuntura tem exigido uma completa readequação a novos processos e à nova dinâmica da profissão. Como exemplo, a disseminação cada vez mais frequente de fake news (notícias falsas) impõe ao profissional de imprensa pressões e riscos ainda maiores. A necessidade de uma checagem rigorosa das informações compete com as constantes demandas por aceleração do ciclo de produção da notícia. 


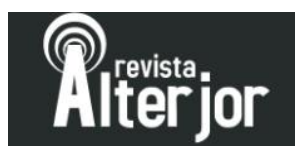

Em meio a tantas mudanças, há valores que devem permanecer firmes, sob risco de comprometer o futuro da atividade jornalística. A obrigação do jornalismo é com o público. O jornalismo deve colocar os interesses do público à frente dos interesses comerciais, políticos e pessoais. O jornalismo deve instrumentar, por meio da informação crível e precisa, os espectadores, ouvintes e leitores, capacitando-os a formarem suas próprias opiniões e convicções. Contudo, não é seu papel conduzir pessoas a determinadas crenças ou ideologias.

Esta ética deve permear todas as etapas do processo jornalístico, incluindo seleção de matérias, coleta de notícias, produção, apresentação e entrega. Os praticantes do jornalismo ético têm a obrigação de buscar e apresentar opiniões e posicionamentos diversos e até mesmo opostos, a fim de preservarem e evidenciarem sua posição central de mediação e, por conseguinte, melhor municiarem seus consumidores com informações que possam ser claramente compreendidas e, quando apropriado, revisitadas e revisadas.

Em tempos como os atuais, de extrema polarização ideológica, as mídias sociais têm sido palco de verdadeiras batalhas de opinião, que vêm inclusive gerando intensos debates sobre a existência ou não de limites à liberdade de expressão. A banalização de agressões dos mais variados tipos - inimagináveis no convívio social antes do advento das mídias sociais -, coloca em risco a observância dos preceitos do livre pensar e da livre manifestação por parte dos cidadãos.

Hoje, como este estudo pode apresentar, os jornalistas se veem diante de um enorme desafio - um dilema que os coloca em confronto interno entre o pleno exercício da liberdade de expressão e a boa gestão de sua imagem e credibilidade profissionais.

Conclui-se que a utilização pelos jornalistas de perfis pessoais nas mídias sociais para verbalizar suas convicções pessoais tem acarretado impactos relevantes na imagem desses profissionais e de seus veículos, ameaçando um dos valores mais caros da atividade jornalística: a credibilidade.

Conforme constatou-se ao longo desta pesquisa, independentemente da inclinação política ou ideológica do profissional, o pleno exercício da liberdade de 


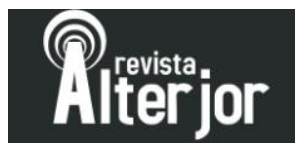

expressão nas mídias sociais vem sendo acompanhado por um certo prejuízo de imagem, pois, ao revelarem abertamente determinadas convicções pessoais, acabam, em certa medida, abdicando da centralidade exigida pelo papel de mediador da informação.

Merece destaque o fato de que o consumidor da notícia não diferencia o cidadão que se manifesta nas mídias sociais do profissional de jornalismo que assina uma matéria. Como ele espera do jornalista uma atuação de fidelidade aos fatos, de busca pela informação correta e de mediação ética, a simples manifestação de uma opinião pessoal pode ser percebida como um alinhamento ideológico capaz de colocar em xeque a credibilidade de suas informações.

Em tese, a credibilidade do profissional de jornalismo deve passar ilesa pelas naturais e esperadas alternâncias no poder entre as diversas vertentes políticas existentes, bem como pelo acalorado debate público entre as diferentes correntes ideológicas ou político-partidárias.

\section{REFERÊNCIAS}

AGUIAR, L.; RODRIGUES, C. Práticas de jornalismo amador em plataformas interativas: uma revisão bibliográfica. In: CONGRESSO BRASILEIRO DE CIÊNCIAS DA COMUNICAÇÃO,38., 2015. Rio de Janeiro. Anais... São Paulo: Intercom, 2015.

ALVES, R. C. Jornalismo digital: dez anos de web e a revolução continua. Comunicação e Sociedade, v. 9, n. 10, p. 93-102, 2012.

ASSIS, E. de. (2017). Influências no jornalismo participativo: um estudo local sobre decisões editoriais tomadas pelo público. Dissertação de Mestrado. Florianópolis: UFSC.

BARSOTTI, A. Jornalista em mutação: do cão de guarda ao mobilizador de audiência. Florianópolis: Insular, 2014

BARSOTTI, A. Uma história da primeira página. Florianópolis: Insular, 2018.

BOKOVA, Irina.Tendências mundiais sobre liberdade de expressão e desenvolvimento da mídia. Brasília: UNESCO, 2016. 108 p. 


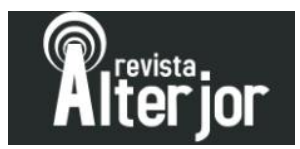

BONNER, William. Graça das redes sociais acabou, 'agora é campo de batalha'. 2020. Disponível em: https://tvefamosos.uol.com.br/noticias/redacao/2020/08/09/ william-bonneraltas-horas-jornal-nacional.htm. Acesso em: 09 ago. 2020.

BRASIL. Constituição (1988). Constituição da República Federativa do Brasil. Brasília: Centro Gráfico, 1988.

CEZAR, Gustavo Buss. As notícias e seus critérios na perspectiva da rede. 2014. Tese (Doutorado em Comunicação Social) - Faculdade de Comunicação Social, Pontifícia Universidade Católica do Rio Grande do Sul, Porto Alegre.

DEBORD, Guy. A sociedade do espetáculo. Rio de Janeiro: Contraponto, 2012.

KARAM, Francisco. Jornalismo ética e liberdade. São Paulo (SP): Summus Editorial, 2014.

KOVACH, Bill; ROSENSTIEL, Tom. Os elementos do jornalismo - O que os jornalistas devem saber e o público deve exigir. São Paulo: Geração Editorial, 2003.

MACCALÓZ, Salete. O Poder Judiciário, os meios de comunicação e opinião pública. Rio de Janeiro: Lumen Juris, 2012.

MARTINS, Luiz da Silva. O jornalismo como teoria democrática. In: CHRISTOFOLETTI, Rogério. Vitrine e Vidraça: Crítica de Mídia e Qualidade no Jornalismo. Portugal, LabCom Books, 2010.

MORAES, D; RAMONET, I.; SERRANO, P. Mídia, poder e contrapoder: da concentração monopólica e democratização da informação. São Paulo, Boitempo; Rio de Janeiro, Faperj: 2013.

NALINI, José Renato. Ética geral e profissional. 12 ed. rev., atual. e ampl. - São Paulo: Editora Revista dos Tribunais, 2015.

PRIMO, A. Interações em rede. Porto Alegre: Sulina, 2013.

SACRAMENTO, Igor. A saúde numa sociedade de verdades. 2018. Revista Eletrônica de Comunicação Informação \& Inovação em Saúde. V.12, n.1.

SANTAELlA, Lúcia. (2009). A ecologia pluralista das mídias locativas. Revista FAMECOS, 15(37), 20-24.

SANTAELLA, Lucia; LEMOS, Renata. Redes Sociais digitais: a cognição conectiva do Twitter. São Paulo: Ed. Paulus, 2010 (Coleção Comunicação)

SILVA, Érica Danielle.; TASSO, Ismara. Prática Discursiva Midiática. Guarapuava, vol. 3 n. 2 (dez. 2012).

VELO, Atila. A história das mídias sociais. Santo André, 2012. Disponível em: $<$ http://redatorweb.com.br/a-historia-das-midias-sociais-um-guia-sobre-a-origem-destefenomenoslideshare/>. Acessado em: 19 mai. 2020. 